\title{
A Structure and Antioxidant Activity Study of Paracetamol and Salicylic Acid
}

\author{
Rosivaldo S. Borges ${ }^{*}$, Tainá G. Barros ${ }^{1}$, Glaécia A. N. Pereira1, João Batista Jr.1, \\ Raimundo F. G. P. Beleza Filho'1, Andrex A. S. Veiga1, Moisés Hamoy², Vanessa J. Mello², \\ Albérico B. F. da Silva ${ }^{3}$, Carlos A. L. Barros ${ }^{1}$ \\ ${ }^{1}$ Núcleo de Estudos e Seleção de Moléculas Bioativas, Instituto de Ciências da Saúde, Universidade Federal do \\ Pará, Belém, Brazil \\ ${ }^{2}$ Laboratório de Farmacologia e Toxicologia de Produtos Naturais, Instituto de Ciências da Saúde, Universidade \\ Federal do Pará, Belém, Brazil \\ ${ }^{3}$ Instituto de Química de São Carlos, Universidade de São Paulo, São Carlos, Brazil \\ Email: ${ }^{\text {rosborg@ufpa.br }}$
}

Received 5 September 2014; revised 13 November 2014; accepted 20 December 2014

Copyright (C) 2014 by authors and Scientific Research Publishing Inc.

This work is licensed under the Creative Commons Attribution International License (CC BY).

http://creativecommons.org/licenses/by/4.0/

c) (i) Open Access

\begin{abstract}
The paracetamol has more antioxidant properties than the salicylic acid on the several oxidative stress-forced models and one possible mechanism is due to electron or hydrogen transfer by the evaluated hydroxyl radicals. The antioxidant mechanism for the compounds studied here was performed by molecular modeling using quantum chemical calculations at the B3LYP level of theory. Our results show that the paracetamol has more antioxidant properties than the salicylic acid in experimental and theoretical studies. The theoretical mechanism show that the hydrogen transfer is more favorable than the electron transfer. From the study it was concluded that the electron abstraction for paracetamol is more favored than salicylic acid.
\end{abstract}

\section{Keywords}

Paracetamol, Salicylic Acid, Phenol Derivatives, NSAIDs, Antioxidant

\section{Introduction}

Even showing no anti-inflammatory effects, the paracetamol has been extensively used as analgesic and antipyretic. Although apparently safe if used in normal therapeutic doses, higher doses of paracetamol can produce hepatic and/or renal injury in humans and in experimental animals [1]. Alternatively, aspirin or acetylsalicylic

${ }^{*}$ Corresponding author. 
acid shows analgesic, antipyretic, anti-inflammatory and antirheumatic actions [2], besides being recently accepted as an effective agent for the prevention of cardiovascular diseases and colorectal cancer [3]-[6]. Despite the mechanisms are still not entirely understood, it has been assumed that the beneficial effects of aspirin on human health depends, at least partly, on the anti-inflammatory properties of the salicylic acid, a compound derived from the hydrolysis of the acetylsalicylic acid in vivo [7]. Both compounds, the paracetamol (1) and the salicylic acid (2) (Figure 1), are phenol derivatives and present antioxidant activity in many biological model of the lipid peroxidation [8]-[11].

The lipid peroxidation is an important mediator of pathos-physiological events and the excessive production of free-radicals in the organism, together with the imbalance between the concentrations of free-radicals and the antioxidant defenses and may be related to the pathogenesis of various diseases such as atherosclerosis, stroke, diabetes mellitus, cancer and inflammatory diseases [12]-[14].

On the other hand, nonsteroidal anti-inflammatory drugs (NSAID) have shown to be a powerful free-radical scavenger. Formed at inflammatory sites, oxidants such as superoxide $\left(\mathrm{O}_{2}^{--}\right)$, hydrogen peroxide $\left(\mathrm{H}_{2} \mathrm{O}_{2}\right)$, hydroxyl ( $\left.\mathrm{HO}^{\circ}\right)$, and hypochlorous acid $(\mathrm{HOCl})$ appear to contribute to the tissue damage in some acute and chronic inflammatory diseases [15].

Human erythrocytes are a good subject to study biological effects caused by free-radicals, since they are both structurally simple and easily obtained. Its membrane is related with damage or protection via free-radical, leading to the investigation of whether they interact with the enzymatic antioxidant defense, accelerate or prevent the $\mathrm{H}_{2} \mathrm{O}_{2}$-induced or -forced lipoperoxidative degradation of erythrocytes membranes, following incubation with the test drugs [8].

In the present study, we evaluate the oxidative stress in erythrocytes with special attention to the pathway involving $\mathrm{H}_{2} \mathrm{O}_{2}$-forced erythrocytic membrane lipid peroxidation with catalase inhibition. The lipid peroxidation was estimated by measurement of thiobarbituric acid-reactive substances (TBARS) and an estimation of the cell response to the oxidative damage was performed through determination of the antioxidant activity of the paracetamol and the salicylic acid compared to trolox. Our biological results were correlated with molecular modeling calculations aiming to contribute for a better understanding on the oxidation mechanism of these phenolic compounds.

\section{Methods}

\subsection{Chemistry}

All chemical reagents used in this study were of analytical grade and purchased from Sigma and Merck Co. The drugs were dissolved in $10 \mathrm{mM}$ Tris-HCl-KCl $(\mathrm{pH} 7.4)$.

\subsection{Erythrocytes Preparation}

The blood samples were obtained from normal healthy donors and do not use NSAID and young people beween 20 - 30 years old. The blood $(10 \mathrm{ml})$ was drawn from an antecubital vein into EDTA anticoagulant solution (20\%). The samples were then centrifuged to separate plasma from the blood cells. Following, the erythrocytes were washed twice with $10 \mathrm{mM}$ Tris-HC1, $150 \mathrm{mM} \mathrm{KCl} \mathrm{(pH} \mathrm{7.4)} \mathrm{and} \mathrm{packed} \mathrm{erythrocytes} \mathrm{were} \mathrm{prepared} \mathrm{in}$ $3000 \mathrm{RPM}$ at $25^{\circ} \mathrm{C}$. All procedures were approved by Human Research Ethics Committee/UFPA (065/06 CEP-CCS/UFPA).

\subsection{Analyses}

The method of Gutteridge et al. [16] was used, after slight modification, to investigate the effect of the paracetamol and salicylic acid on membrane lipid peroxidation induced by $\mathrm{H}_{2} \mathrm{O}_{2}$. A volume of $0.2 \mathrm{~mL}$ of the packed erythrocytes were added to $0.8 \mathrm{~mL}$ of Tris- $\mathrm{HCl}$ azide $(10.0 \mathrm{mM}, \mathrm{pH} 7.4)$ in $150.0 \mathrm{mM} \mathrm{KCl}(10 \mathrm{mM}$ sodium azide) and incubated with $1.0 \mathrm{~mL}$ of the appropriate amount of test drug in a shaking waterbath at $37.0^{\circ} \mathrm{C}$ for 30 minutes to allow the catalase to be inactivated by azide within the cells. After adding $0.5 \mathrm{~mL}$ of $30.0 \mathrm{mM} \mathrm{H}_{2} \mathrm{O}_{2}$ (in $150.0 \mathrm{mM} \mathrm{NaCl}$ ), the cells were incubated for 1 (one) hour at the same conditions. The reaction was terminated by adding $0.5 \mathrm{~mL}$ of $28.0 \%$ TCA (w/v). All tubes were centrifuged at $4000 \mathrm{x}$ g for 10 minutes and $2.0 \mathrm{~mL}$ of the supernatant was collected. A volume of $1.0 \mathrm{~mL}$ of TBA $1.0 \%(\mathrm{w} / \mathrm{v}$; in $0.05 \mathrm{M} \mathrm{NaOH})$ was added to the portion of supernatant and the mixture was heated at $100^{\circ} \mathrm{C}$ for 15 minutes. After cooling, the mixture absorbance measured was of $532 \mathrm{~nm}$. 


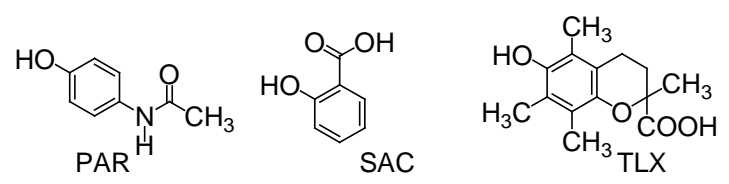

Figure 1. Chemical structure of paracetamol (PAR), salicylic acid (SAC), and trolox (TLX).

\subsection{Statistics}

The data obtained, presented as mean values \pm the standard error of the mean (SEM), were analyzed by one-way of variance (ANOVA) and Student-Newman-Keuls post hoc tests for the significant interrelation between the various groups using the SigmaPlot software. The value of $p \leq 0.05$ was considered to be significantly different from the control.

\subsection{Theoretical Study}

Prior to any Density-Functional Theory (DFT) [17] calculation, both the paracetamol and the salicylic acid structures were submitted to a semi-empirical PM3 [18] geometry conformational search. Among the physical and the electronic descriptors (variables) with potential relevance for the hypothetical mechanism examined for both compounds, only the ionization potential (IP) of their neutral and anionic forms were selected. After the initial optimization with PM3, the geometry of the paracetamol and of the salicylic acid were re-optimized with DFT using B3LYP (three parameter hybrid exchange functional of Becke with the Lee-Yang-Parr correlation functional) [19] [20] and 6-31G(d) basis sets [21]. Only the most stable conformation of each compound was then used in our study.

The IP was calculated as the energy difference between a neutral molecule and the respective cation freeradical as showed in Equation (1).

$$
\mathrm{IP}=E \mathrm{ArOH}^{+}-\mathrm{EArOH}
$$

The bond dissociation energies of the phenol group ( $\mathrm{BDE}_{\mathrm{OH}}$ ) or semiquinone formation was calculated as the energy difference between a neutral molecule and the respective semiquinone plus the hydrogen radical as defined in Equation (2).

$$
\mathrm{BDE}_{\mathrm{OH}}=\left(\mathrm{EArO}^{\cdot}+\mathrm{EH}^{\cdot}\right)-\mathrm{EArOH}
$$

Radical stability is calculated by electron transfer related to trolox. In this case, the radical stability by electron transfer is determined by stabilization energies calculation ( $\Delta$ Eiso), as showed in Equation (3), where paracetamol and salicylic acid derivatives is $\mathrm{ArOH}$ and tolox is $\mathrm{PhOH}$.

$$
\Delta \mathrm{E}_{\text {iso }}=\left(\mathrm{ArOH}^{\cdot+}+\mathrm{PhOH}\right)-\left(\mathrm{ArOH}+\mathrm{PhOH}^{\cdot+}\right)
$$

\section{Results}

\subsection{Lipid Peroxidation in Human Erythrocytes}

Figure 2 shows the antioxidant effect of NSAID phenol derivatives paracetamol (PAR) and salicylic acid (SAC) on $\mathrm{H}_{2} \mathrm{O}_{2}$ (30.0 mM)-induced lipid peroxidation in human erythrocytes compared to trolox (TLX). The TBARS concentrations for the TLX are significantly smaller than that for PAR or SAC. On $0.25 \mathrm{mM}$ (M1) the TBARS concentration was increased by the no significantly amount of $8 \%$ for the PAR and of $43 \%$ for the SAC ( $\leq$ $0.01)$. However, in $0.5 \mathrm{mM}$ (M2), the TBARS concentrations were reduced by $25 \%$ for PAR ( $\leq 0.01$ ) and it was increased to no significantly amount of $6 \%$ for SAC. The same tendency is observed for $1.0 \mathrm{mM}$ (M3) of concentration, for which the TBARS level was reduced by $43 \%$ for PAR $(\mathrm{p} \leq 0.01)$ and increased by $8 \%$ for the SAC ( $\leq 0.05)$. The TBARS concentrations for the TLX were significantly reduced in all concentration, i.e. $42 \%$ (M1), 66\% (M2), and 80\% (M3) (p $\leq 0.001)$.

\subsection{Structure and Activity Relationship}

The antioxidant capacity of these phenol derivatives can be considered using theoretical methods. Hence, a 
structure and activity relationship (SAR) study was performed here in order to correlate biological values and theoretical property, such as electronic parameters by electron or hydrogen transfers. These parameters can be observed in Table 1.

\section{Discussion}

\subsection{Lipid Peroxidation in Human Erythrocytes}

The results show that the antioxidant activity of paracetamol in the human erythrocytes is more expressive than that of salicylic acid. However, it is known that paracetamol can cause severe hepatic necrosis at high doses both in human and animals [22], since it can be activated by peroxidases of the cytochrome P-450 producing quinones and semiquinones forms, both active oxygen free-radical species [23] [24]. Furthermore, it has been shown that one of the main effects of the paracetamol toxicity is the depletion of cellular gluthatione (GSH) [24], a necessary compound for the termination step of the lipid peroxidation as antioxidant defense. It has been suggested that paracetamol toxic dose treatment induces metabolic and membrane alteration making RBCs prone to hemolysis [25]. On the contrary, the salicylic acid does not present this effect at the same condition and concentration. Nevertheless, the paracetamol has showed antioxidant activity in vitro while the acetylsalicylic acid does not present it. Moreover, the salicylic acid is a compound derived from hydrolysis of acetylsalicylic acid (aspirin) [26].

It has recently been shown that the paracetamol administration in rats induces an increasing of serotonin, norepinephrine and lipid peroxidation levels in the brain [27]. This drug alone or combined with aspirin exhibits antioxidant effects in the brain using the rat brain homogenates [28].

The study performed in this work shows that the paracetamol and the salicylic acid have the potential to limit these undesirable effects, qualities that satisfy requirements for using them as cytoprotective agents in degenerative cells disorders, for example. We found that the potent free-radical scavenger and lipid peroxidation inhibition of paracetamol affords only a protection against $\mathrm{H}_{2} \mathrm{O}_{2}$-induced oxidative stress in human erythrocytes. The salicylic acid, which has less antioxidant ability, as shown in the present study, was capable of fully reviving the erytrhocytes damage caused by $\mathrm{H}_{2} \mathrm{O}_{2}$ only when combined with other phenol derivatives.

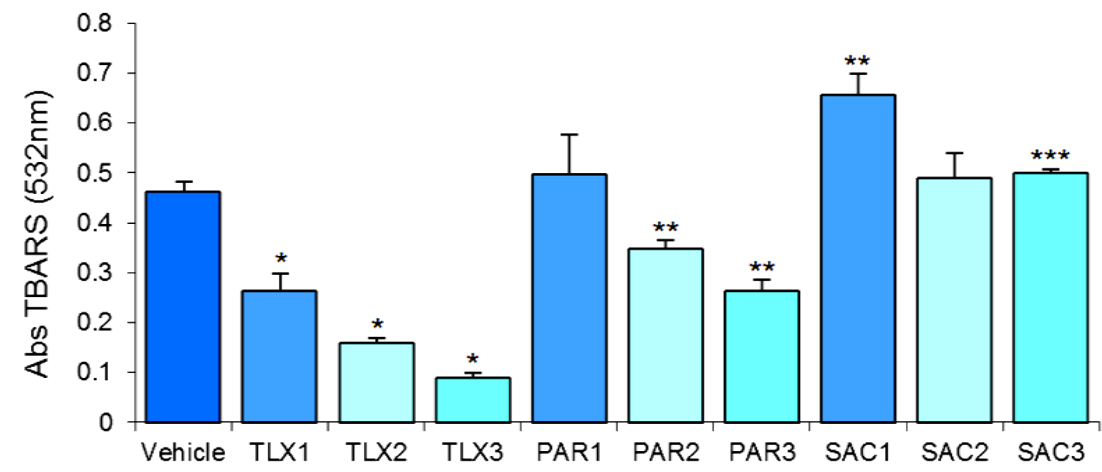

Figure 2. The antioxidant effect of trolox (TLX), paracetamol (PAR), and salicylic acid (SAC) on $\mathrm{H}_{2} \mathrm{O}_{2}(30 \mathrm{mM})$-induced lipid peroxidation in human erythrocytes at $0.25 \mathrm{mM}$ (M1), $0.5 \mathrm{mM}$ (M2), and $1.0 \mathrm{mM}$ (M3). Each bar represents the mean \pm S.E.M; $n=3, p \leq 0.001\left(^{*}\right), p \leq 0.01\left(^{* *}\right)$, and $p \leq 0.05\left(^{* * *}\right)$.

Table 1. Theoretical parameters for the antioxidant capacity of paracetamol (PAR), salicylic acid (SAC), and trolox (TLX).

\begin{tabular}{cccccc}
\hline \multirow{2}{*}{ Compound } & \multicolumn{5}{c}{ Theoretical Properties } \\
\cline { 2 - 6 } & $\begin{array}{c}\text { HOMO } \\
(\mathrm{Ev})\end{array}$ & $\begin{array}{c}\text { LUMO } \\
(\mathrm{Ev})\end{array}$ & $\begin{array}{c}\mathrm{IP} \\
(\mathrm{kcal} / \mathrm{mol})\end{array}$ & $\begin{array}{c}\mathrm{BDE} \\
(\mathrm{kcal} / \mathrm{mol})\end{array}$ & $\begin{array}{c}\Delta \mathrm{E}_{\text {iso }} \\
(\mathrm{kcal} / \mathrm{mol})\end{array}$ \\
\hline Paracetamol (PAR) & -5.48 & -0.08 & 171.32 & 93.54 & 11.82 \\
Salicylic acid (SAC) & -6.26 & -1.46 & 192.61 & 111.82 & 33.11 \\
Trolox (TLX) & -5.07 & 0.07 & 158.49 & 89.84 & 0 \\
\hline
\end{tabular}


Our results are in agreement with previous reports where paracetamol has been shown to significantly reduce the $\mathrm{KCN}$-induced superoxide anion generation as well as the KCN-induced lipid peroxidation. When paracetamol and salicylic acid are used in combination, the cytoprotective effect is increased [29]. Similarly, when administered prior to 1-methyl-4-phenyl-1,2,3,6-tetrahydropyridine (MPTP), the aspirin has been shown to attenuate striatal dopamine depletion in mice [30]-[32]. The salicylic acid, an aspirin metabolite, has also been shown to afford protection against MPTP- or 1-methyl-4-phenyl pyridinium (MPP+)-induced dopaminergic toxicity in mice [33] and rats [34].

\subsection{Structure and Activity Relationship}

The theoretical results for the hypothetical mechanism for paracetamol (PAR) and salicylic acid (SAC) by hydrogen transfers using $\triangle$ Eiso are related to trolox (TLX) [35]. Thus, paracetamol is approximately by 11.82 $\mathrm{kcal} \cdot \mathrm{mol}^{-1}$ and salicylic acid is $33.11 \mathrm{kcal} \cdot \mathrm{mol}^{-1}$ (Table 1 ). Therefore, the paracetamol is more reactive than the salicylic acid. In fact, the spin density calculation reveals that the semiquinone free-radical of paracetamol has more resonance structures in the aromatic ring than that of the salicylic acid. Therefore, DFT calculations indicated that the paracetamol presents larger stability for the semiquinone free-radical formation compared to the salicylic acid [26] [36]-[40].

Therefore, electron-donating groups as phenol and acetamide ortho or para substituted decrease the IP and $\mathrm{BDE}_{\mathrm{OH}}$ values, while electron-withdrawing as carboxyl acid substituent increases the IP and $\mathrm{BDE}_{\mathrm{OH}}$ values. Consequently, the salicylic acid showed the highest IP and $\mathrm{BDE}_{\mathrm{OH}}$ values, while the paracetamol showed the lowest IP and $\mathrm{BDE}_{\mathrm{OH}}$ values.

These results show the reason why the oxidation of the paracetamol is more favored than that of the salicylic acid when the electron or hydrogen abstractions are taken into account. Nonetheless, the DFT calculations indicate that paracetamol present the lowest energy barriers when compared to trolox. Therefore, these results can explain the possible mechanism for both salicylic acid and paracetamol on the forced oxidative stress in human erythrocytes. All theoretical parameters, such as HOMO, LUMO, ionization potentials (IP), and hydroxyl bond dissociation energies $\left(\mathrm{BDE}_{\mathrm{OH}}\right)$ of the studied molecules showed good correspondence with the antioxidant activity evaluated by TBARS levels.

The trolox has shown the lowest values for HOMO $(-5.07 \mathrm{eV})$, LUMO $(0.07 \mathrm{eV})$, IP $\left(158.49 \mathrm{kcal} \cdot \mathrm{mol}^{-1}\right)$, and $\mathrm{BDE}_{\mathrm{OH}}\left(89.84 \mathrm{kcal} \cdot \mathrm{mol}^{-1}\right)$. Moreover, the salicylic acid has the highest values for HOMO $(-6.24 \mathrm{eV})$, LUMO $(-1.46 \mathrm{eV})$, IP $\left(192.61 \mathrm{kcal} \cdot \mathrm{mol}^{-1}\right)$, and $\mathrm{BDE}_{\mathrm{OH}}\left(111.82 \mathrm{kcal} \cdot \mathrm{mol}^{-1}\right)$. Nonetheless, for the paracetamol all values were intermediates HOMO $(-5.48 \mathrm{eV})$, LUMO $(-0.08 \mathrm{eV})$, IP $\left(171.32 \mathrm{kcal} \cdot \mathrm{mol}^{-1}\right)$, and BDE $\mathrm{OH}\left(93.54 \mathrm{kcal} \cdot \mathrm{mol}^{-1}\right)$ compared to trolox and salicylic acid.

\section{Conclusion}

The $\mathrm{H}_{2} \mathrm{O}_{2}$-induced lipid peroxidation in human erythrocytes showed significant inhibition on TBARS formation for the trolox. The paracetamol exhibited more potent inhibition of lipid peroxidation activity than the salicylic acid. These effects may be attributed to the electron-donating groups as phenol and acetamide ortho or para substituted for the paracetamol and the salicylic acid decrease the IP and $\mathrm{BDE}_{\mathrm{OH}}$ values. These theoretical properties explain that the electron abstraction mechanism is more favored for paracetamol than salicylic acid.

\section{Acknowledgements}

The authors would like to thank the CNPq (Brazilian Agency) for the financial support.

\section{References}

[1] Mitchell, J.R., Jollow, D.J., Potter, W.Z., Davis, D.C., Gillette, J.R. and Brodie, B.B. (1973) Acetaminophen-Induced Hepatic Necrosis. I. Role of Drug Metabolism. Journal of Pharmacology and Experimental Therapeutics, 187, 185194.

[2] Stanley, P. and Hegedus, R. (2000) Aspirin—The First Hundred Years. Biologist, 47, 269-271.

[3] Marcus, A.J. (1995) Aspirin as Prophylaxis against Colorectal Cancer. The New England Journal of Medicine, 333, 656-658. http://dx.doi.org/10.1056/NEJM199509073331011

[4] Herbert, P.R. and Hennekens, C.H. (2000) An Overview of the 4 Randomized Trials of Aspirin Therapy in the Primary 
Prevention of Vascular Disease. Archives of Internal Medicine, 160, 3123-3127. http://dx.doi.org/10.1001/archinte.160.20.3123

[5] Lowe, G.D.O. (2001) Who Should Take Aspirin for Primary Prophylaxis of Coronary Heart Disease? Heart, 85, 245246. http://dx.doi.org/10.1136/heart.85.3.245

[6] Gasche, C. (2004) Review Article: The Chemoprevention of Colorectal Carcinoma. Alimentary Pharmacology \& Therapeutics, 20, 31-35. http://dx.doi.org/10.1111/j.1365-2036.2004.02045.x

[7] Higgs, G.A., Salmon, J.A., Henderson, B. and Vane, J.R. (1987) Pharmacokinetics of Aspirin and Salicylate in Relation to Inhibition of Arachidonate Cyclooxygenase and Antiinflammatory Activity. Proceedings of the National Academy of Sciences of the United States of America, 84, 1417-1420. http://dx.doi.org/10.1073/pnas.84.5.1417

[8] Orhan, H. and Sahin, G. (2001) In Vitro Effects of NSAIDS and Paracetamol on Oxidative Stress-Related Parameters of Human Erythrocytes. Experimental and Toxicologic Pathology, 53, 133-140. http://dx.doi.org/10.1078/0940-2993-00179

[9] Dinis, T.C.P., Madeira, V.M.C. and Almeida, L.M. (1994) Action of Phenolic Derivatives (Acetaminophen, Salicylate and 5-Aminosalicylate) as Inhibitors of Membrane Lipid Peroxidation and as Peroxyl Radical Scavengers. Archives of Biochemistry and Biophysics, 315, 161-169. http://dx.doi.org/10.1006/abbi.1994.1485

[10] Maharaj, D.S., Saravanan, K.S., Maharaj, H., Mohanakumar, K.P. and Daya, S. (2004) Acetaminophen and Aspirin Inhibit Superoxide Anion Generation and Lipid Peroxidation, and Protect against 1-Methyl-4-phenyl Pyridinium-Induced Dopaminergic Neurotoxicity in Rats. Neurochemistry International, 44, 355-360. http://dx.doi.org/10.1016/S0197-0186(03)00170-0

[11] Maharaj, H., Maharaj, D.S. and Daya, S. (2006) Acetylsalicylic Acid and Acetaminophen Protect against MPP ${ }^{+}$-Induced Mitochondrial Damage and Superoxide Anion Generation. Life Sciences, 78, 2438-2443. http://dx.doi.org/10.1016/j.lfs.2005.10.002

[12] Hall, E.D. (1993) Role of Oxygen Radicals in Central Nervous System Trauma. In: Tarr, M. and Samson, F., Eds., Oxygen Free-Radicals in Tissue Damage, Birkhäuser, Boston, 153-173. http://dx.doi.org/10.1007/978-1-4615-9840-4

[13] Kasapoglu, M. and Ozben, T. (2001) Alterations of Antioxidant Enzymes and Oxidative Stress Markers in Aging. Experimental Gerontology, 36, 209-220. http://dx.doi.org/10.1016/S0531-5565(00)00198-4

[14] Sudha, K., Rao, A.V. and Rao, A. (2001) Oxidative Stress and Antioxidants in Epilepsy. Clinica Chimica Acta, 303, 19-24. http://dx.doi.org/10.1016/S0009-8981(00)00337-5

[15] Halliwell, B. and Gutteridge, J.M.C. (1985) Importance of Free-Radicals and Catalytic Metals in Human Disease. Molecular Aspects of Medicine, 8, 89-193. http://dx.doi.org/10.1016/0098-2997(85)90001-9

[16] Gutteridge, J.M.C., Quinlan, G.J., Clark, I. and Halliwell, B. (1985) Aluminium Salts Accelerate Peroxidation of Membrane Lipids Stimulated by Iron Salts. Biochimica et Biophysica Acta, 835, 441-447. http://dx.doi.org/10.1016/0005-2760(85)90113-4

[17] Parr, R.G. and Yang, W. (1989) Density Functional Theory of Atoms and Molecules. Oxford University Press, New York.

[18] Stewart, J.J.P. (1989) Optimization of Parameters for Semi-Empirical Methods I. Method. Journal of Computational Chemistry, 10, 209-220. http://dx.doi.org/10.1002/jcc.540100208

[19] Becke, A.D. (1993) Density-Functional Thermochemistry. III. The Role of Exact Exchange. The Journal of Chemical Physics, 98, 5648-5652. http://dx.doi.org/10.1063/1.464913

[20] Lee, C., Yang, W.R. and Parr, G.R. (1988) Development of the Colle Salvetti Correlation-Energy Formula into a Functional of the Electron Density. Physical Review B, 37, 785-789. http://dx.doi.org/10.1103/PhysRevB.37.785

[21] Hehre, W.J., Radom, L., Schleyer, P.V.R. and Pople, J.A. (1986) Ab Initio Molecular Orbital Theory. John Wiley and Sons, New York.

[22] Prescott, L.F. (1983) Paracetamol Overdosage. Drugs, 25, 290-314. http://dx.doi.org/10.2165/00003495-198325030-00002

[23] Alves, C.N., Borges, R.S. and Da Silva, A.B.F. (2006) Density Functional Theory Study of Metabolic Derivatives of the Oxidation of Paracetamol. International Journal of Quantum Chemistry, 106, 2617-2623. http://dx.doi.org/10.1002/qua.20992

[24] Suhail, M. and Ahmad, I. (1995) In Vivo Effects of Acetaminophen on Rat RBC and Role of Vitamin E. Indian Journal of Experimental Biology, 33, 269-271.

[25] Burton, G.W. and Ingold, K.U. (1981) Autoxidation of Biological Molecules. 1. Antioxidant Activity of Vitamin E and Related Chain-Breaking Phenolic Antioxidants in Vitro. Journal of the American Chemical Society, 103, 6472-6477. http://dx.doi.org/10.1021/ja00411a035

[26] Albano, E., Rundgren, M., Harvison, P.J., Nelson, S.D. and Moldeus, P. (1985) Mechanisms of N-Acetyl-p-benzoquinone 
Imine Cytotoxicity. Molecular Pharmacology, 28, 306-311.

[27] Courade, J.P., Caussade, F., Martin, K., Besse, D., Delchambre, C., Hanoun, N., Hamon, M., Eschalier, A. and Cloarec, A. (2001) Effects of Acetaminophen on Monoaminergic Systems in the Rat Central Nervous System. Naunyn-Schmiedeberg's Archives of Pharmacology, 364, 534-537. http://dx.doi.org/10.1007/s002100100484

[28] Daya, S. and Anoopkumar-Dukie, S. (2000) Acetaminophen Inhibits Liver Tryptophan 2,3-Dioxygenase Activity with a Concomitant Rise in Brain Serotonin Levels and a Reduction in Urinary 5-Hydroxyindole Acetic Acid. Life Sciences, 67, 235-240. http://dx.doi.org/10.1016/S0024-3205(00)00629-9

[29] Daya, S., Walker, R.B. and Anoopkumar-Dukie, S. (2000) Cyanide-Induced Free-Radical Production and Lipid Peroxidation in Rat Brain Homogenate Is Reduced by Aspirin. Metabolic Brain Disease, 15, 203-210. http://dx.doi.org/10.1007/BF02674529

[30] Casper, D., Yaparpalvi, U., Rempel, N. and Werner, P. (2000) Ibuprofen Protects Dopaminergic Neurons against Glutamate Toxicity in Vitro. Neuroscience Letters, 289, 201-204. http://dx.doi.org/10.1016/S0304-3940(00)01294-5

[31] Aubin, N., Curet, O., Deffois, A. and Carter, C. (1998) Aspirin and Salicylate Protect against MPTP-Induced Dopamine Depletion in Mice. Journal of Neurochemistry, 71, 1635-1642. http://dx.doi.org/10.1046/j.1471-4159.1998.71041635.x

[32] Teismann, P. and Ferger, B. (2001) Inhibition of the Cyclooxygenase Isoenzymes COX-1 and COX-2 Provide Neuroprotection in the MPTP-Mouse Model of Parkinson's Disease. Synapse, 39, 167-174. http://dx.doi.org/10.1002/1098-2396(200102)39:2<167::AID-SYN8>3.0.CO;2-U

[33] Mohanakumar, K.P., Muralikrishnan, D. and Thomas, B. (2000) Neuroprotection by Sodium Salicylate against 1-Methyl-4-phenyl-1,2,3,6-tetrahydropyridine-Induced Neurotoxicity. Brain Research, 864, 281-290. http://dx.doi.org/10.1016/S0006-8993(00)02189-2

[34] Sairam, K., Saravanan, K.S., Banerjee, R. and Mohanakumar, K.P. (2003) Non-Steroidal Anti-Inflammatory Drug Sodium Salicylate, but Not Diclofenac or Celecoxib, Protects against 1-Methyl-4-phenyl Pyridinium-Induced Dopaminergic Neurotoxicity in Rats. Brain Research, 966, 245-252. http://dx.doi.org/10.1016/S0006-8993(02)04174-4

[35] Queiroz, A.N., Gomes, B.A.Q., Moraes Jr., W.M. and Borges, R.S. (2009) A Theoretical Antioxidant Pharmacophore for Resveratrol. European Journal of Medicinal Chemistry, 44, 1644-1649. http://dx.doi.org/10.1016/j.ejmech.2008.09.023

[36] Diniz, J.E.M., Borges, R.S. and Alves, C.N. (2004) A DFT Study for Paracetamol and 3,5-Disubstituted Analogues. Journal of Molecular Structure: THEOCHEM, 673, 93-97. http://dx.doi.org/10.1016/j.theochem.2003.12.002

[37] Freire, A.D.T., Landivar, L.M.C., Queiroz, A.N. and Borges, R.S. (2009) A Theoretical Study for Oxidative Metabolism of Salicylates. Journal of Computational and Theoretical Nanoscience, 6, 1140-1142. http://dx.doi.org/10.1166/jctn.2009.1157

[38] Silva, J.R., Queiroz, L.M.D., Queiroz, A.N., Souza, P.J.C. and Borges, R.S. (2011) A Theoretical Study of Paracetamol acyl-Ether Derivatives. Journal of Computational and Theoretical Nanoscience, 8, 670-675. http://dx.doi.org/10.1166/jctn.2011.1738

[39] Borges, R.S., Mendes, A.P.S., Silva, B.H.S., Alves, C.N. and Nascimento, J.L.M. (2011) A Theoretical Study of Salicylate Oxidation for ADME Prediction. Medicinal Chemistry Research, 20, 269-273. http://dx.doi.org/10.1007/s00044-010-9320-7

[40] Motozaki, W., Nagatani, Y., Kimura, Y., Endo, K., Takemura, T., Kurmaev, E.Z. and Moewes, A. (2011) Evaluation of Antioxidant Activity and Electronic Structure of Aspirin and Paracetamol. Journal of Molecular Structure, 985, 6369. http://dx.doi.org/10.1016/j.molstruc.2010.10.021 
Scientific Research Publishing (SCIRP) is one of the largest Open Access journal publishers. It is currently publishing more than 200 open access, online, peer-reviewed journals covering a wide range of academic disciplines. SCIRP serves the worldwide academic communities and contributes to the progress and application of science with its publication.

Other selected journals from SCIRP are listed as below. Submit your manuscript to us via either submit@scirp.org or Online Submission Portal.
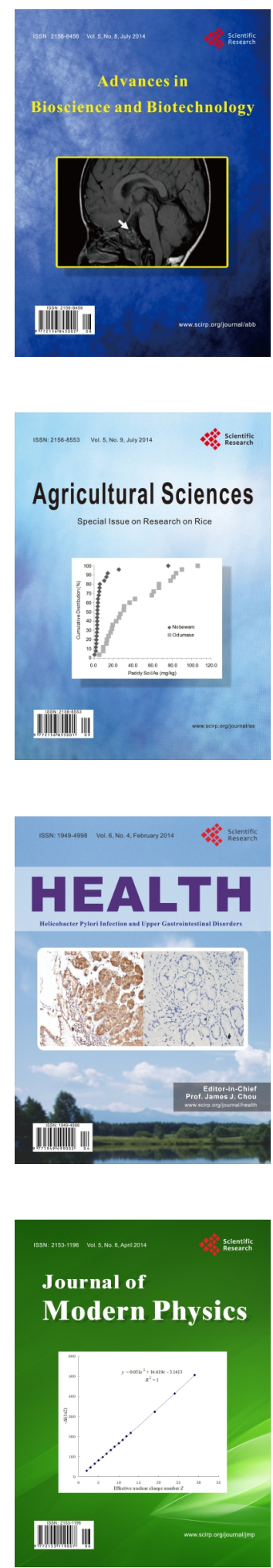
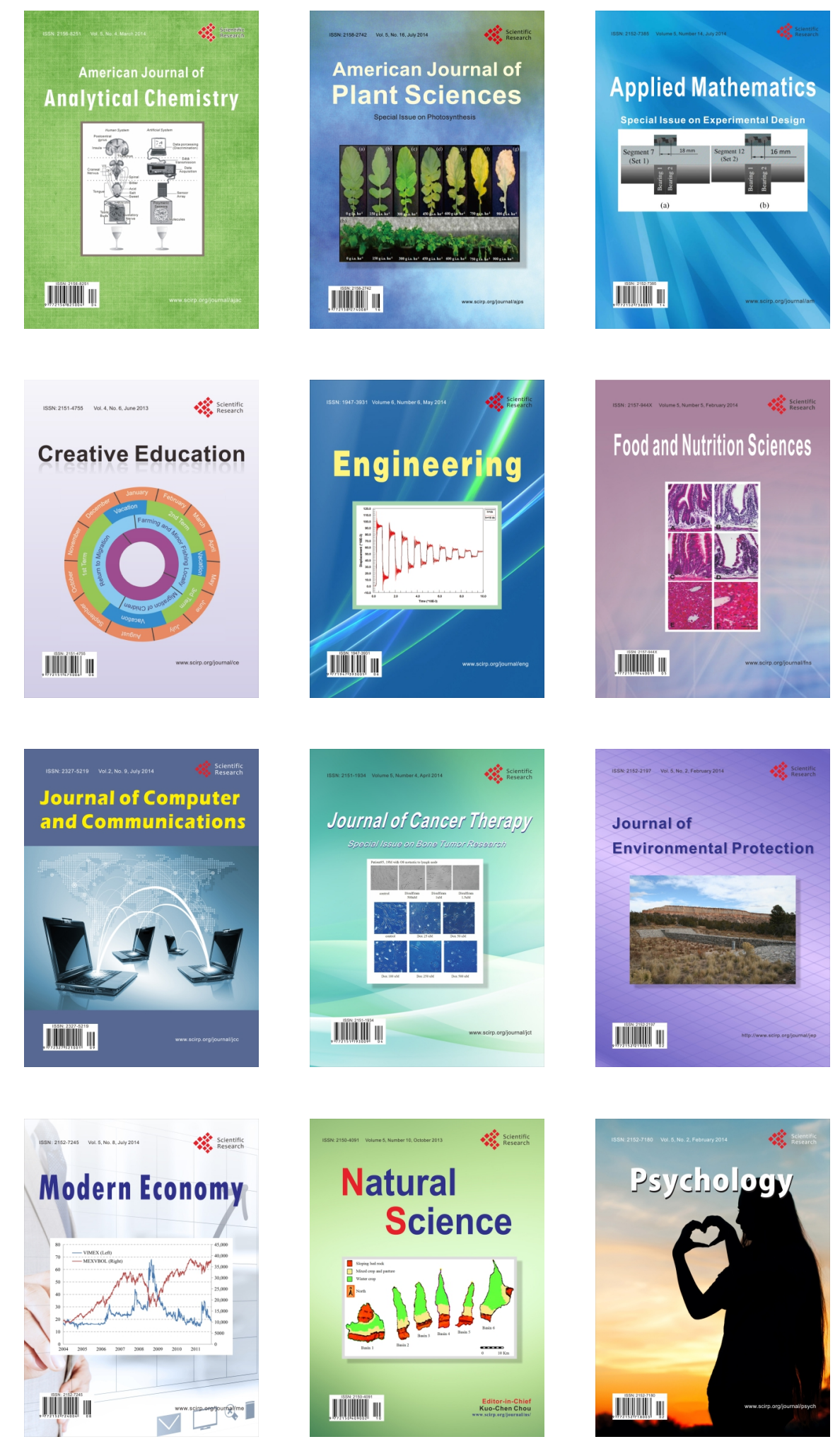